\title{
Experiência, narrativa e conhecimento: a perspectiva do psiquiatra e a do usuário
}

$1{ }^{1}$ Octavio Serpa Junior, 2 Rosana Onocko Campos, ${ }^{3}$ Nuria Malajovich,

${ }^{4}$ Ana Maria Pitta, ${ }^{5}$ Alberto Giovanello Diaz, ${ }^{6}$ Catarina Dahl, ${ }^{7}$ Erotildes Leal I

Resumo: O presente estudo, realizado em parceria entre UFRJ, UNICAMP e UFBA, pretendeu conhecer a experiência das pessoas com o diagnóstico de transtorno do espectro esquizofrênico, em tratamento nos CAPS, e a experiência dos psiquiatras inseridos na rede pública de atenção à saúde mental. Narrativas relacionadas ao processo saúde-doença, no caso de pessoas com diagnóstico de esquizofrenia, e narrativas sobre o processo de formulação do diagnóstico de esquizofrenia, prognóstico e tratamento, no caso dos psiquiatras, foram estudadas. Este é um estudo qualitativo, multicêntrico, informado pelas abordagens teóricas da Análise Interpretativa Fenomenológica e da Antropologia médica, realizado nas cidades de Campinas, Rio de Janeiro e Salvador. A principal ferramenta metodológica empregada para produção das narrativas foram os grupos focais. Técnicas da entrevista de explicitação foram incorporadas. As categorias identificadas no estudo - Experiência de Adoecimento, Diagnóstico de Esquizofrenia, Estigma Social, Experiência de Restabelecimento e Tratamento e o Contexto Dinâmico dos CAPS - e as narrativas que as compuseram foram apresentadas e discutidas com o propósito de dar visibilidade aos elementos que caracterizam as narrativas-experiências dos parcipantes e indicar o modo como se configura sua complexidade.

> Palavras-chave: experiência de adoecimento; narrativa; esquizofrenia.

\author{
1 Universidade Federal do \\ Rio de Janeiro, Instituto de \\ Psiquiatria. Rio de Janeiro-RJ, \\ Brasil. Endereço eletrônico: \\ domserpa@ipub.ufrj.br \\ 2 Universidade Estadual de \\ Campinas, Faculdade de \\ Ciencias Médicas, Saúde \\ Coletiva. Campinas-SP, Brasil. \\ Endereço eletrônico: rosanaoc@ \\ mpc.com.br \\ 3 Universidade Federal \\ Fluminense, Psicologia. Rio \\ das Ostras-RJ, Brasil. Endereço \\ eletrônico: nuriamalajovich@ \\ gmail.com \\ 4 Universidade Católica de \\ Salvador. Salvador-BA, Brasil. \\ Endereço eletrônico: ana.maria. \\ pitta@gmail.com \\ 5 Universidade Nacional de \\ Rosário. Rosário, Argentina. \\ Endereço eletrônico: algiova@ \\ gmail.com \\ 6 Universidade Federal do Rio \\ de Janeiro, Psiquiatria. Rio de \\ Janeiro-RJ, Brasil. Endereço \\ eletrônico: catdahl@hotmail. \\ com \\ 7 Universidade Federal do Rio \\ de Janeiro, Medicina. Macaé-RJ \\ Brasil. Endereço eletrônico: \\ eroleal@gmail.com
}

Recebido em: 28/07/2014 Aprovado em: 13/10/2014 
Em meados do século passado, o processo de transformação da assistência psiquiátrica engendrou, no mundo ocidental, a reorientação do modelo de assistência em saúde mental. Foram eixos desse processo a desinstitucionalização dos pacientes de longa permanência nas instituições psiquiátricas, a progressiva (re)inserção dessas pessoas na vida social e a criação de uma rede de serviços comunitários de saúde mental (THORNICROFT; TANSELLA, 2008). O modelo de atenção comunitária à saúde mental preocupava-se com o diagnóstico e tratamento dos transtornos mentais, mas não só. Por considerar o adoecimento mental um processo complexo, buscava, através da reabilitação psicossocial, tratar igualmente dos seus impactos sobre a vida do adoecido. Ou seja, as desabilidades (disabilities) experimentadas por pessoas diagnosticadas com transtornos mentais graves, como por exemplo a esquizofrenia, constituía questão para o tratamento. A satisfação das necessidades individuais dos usuários, a incorporação da experiência subjetiva dos mesmos, assim como das questôes que envolvem as diferentes esferas da vida cotidiana (trabalho, família, lazer...), tornaram-se eixos a serem considerados no desenho do cuidado em saúde, ampliando a própria ideia de tratamento.

No Brasil, em consonância com a tendência mundial de transformação da assistência psiquiátrica acima referida, iniciou-se, em fins dos anos 1970, um processo de reformulação da assistência psiquiátrica pública que, nas décadas seguintes, pautou a política pública de assistência em Saúde Mental. A partir do ano de 2002, basicamente dois eixos - redução dos leitos hospitalares e criação de uma rede de atenção à saúde mental, de base comunitária e territorial, para o atendimento a pessoas com transtornos mentais graves e persistentes sustentaram a direcionalidade da política pública de Saúde Mental. Foi neste cenário que surgiram os Centros de Atenção Psicossocial (CAPS), equipamentos "estratégicos" (LEAL; DELGADO, 2007, p. 137) que visam tanto a promoção da saúde/saúde mental quanto o desenvolvimento de práticas clínicas promotoras de atenção integral e a reabilitação psicossocial das pessoas diagnosticadas com transtornos mentais graves.

Transcorridos 12 anos da publicação da portaria que instituiu os CAPS como dispositivo estratégico desta política (BRASIL, 2002), o desafio que ora se coloca é o da radicalização da centralidade do usuário no desenho e nas açôes de cuidado (ONOCKO CAMPOS, 2001) neste e nos demais serviços 
que compõem hoje a rede territorial de serviços comunitários. Esforços têm sido feitos nesta direção. Dentre eles, citamos a tentativa de mudar o modo de tratar as narrativas e experiências das pessoas adoecidas. Consideradas também como índice da condição existencial (GOLDBERG, 1996; TENÓRIO, 2001), as narrativas podem, e devem, deixar de ser consideradas apenas no registro da patologia, o que configuraria mais um impulso na direção da promoção de uma relação e um lugar social diferentes para a experiência da loucura. A necessidade de diálogo com a experiência vivida do usuário intensifica-se nesse cenário. Deixar-se iluminar por esta experiência apresenta-se como condição para auxiliar a pessoa adoecida na lida com seu processo de adoecimento, a compreender sua própria experiência, a reduzir estigma e a criar condições de possibilidades mais auspiciosas para sua vida presente e futura.

Esse tipo de inciativa, que é também do âmbito da prática clínica, não se dá, todavia, de forma simples e automática no cotidiano dos serviços. Recentemente, alguns autores têm indicado que os serviços comunitários de saúde mental ainda encontram importantes obstáculos e desafios para superar o cuidado centrado no modelo biomédico e no hospital psiquiátrico (ALVERGA; DIMENSTEIN, 2006; BEZERRA, 2007; MENEZES; YASUI, 2009). A força da ideia de que a evolução dos transtornos mentais depende única e exclusivamente das variáveis relacionadas ao modelo biomédico (etiologia, diagnóstico, prognóstico, agudeza e cronicidade, entre outras) e que prescinde da atmosfera histórico-cultural e sócio-ambiental que envolve o sujeito adoecido, seu modo de ser-no-mundo, de se relacionar com os outros e de viver e compreender a própria experiência de adoecimento (LEAL; SERPA JR.; MUÑOZ, 2007), constituem alguns destes importantes obstáculos.

A estes empecilhos, ligam-se outros de igual relevância. Citamos, por exemplo, os limites impostos pela tradição diagnóstica e clínica pautada na Psicopatologia Descritiva, perspectiva hegemônica no campo, que, pela visão das alterações psicopatológicas que oferece, pouco contribui para a promoção de práticas inclusivas e cidadãs em saúde mental. Benedetto Saraceno (1997, 1999) foi um dos autores que, há mais de uma década, indicou os limites desta tradição para operar um cuidado transformador, centrado no usuário e situado no território.

A valoração negativa da experiência existencial decorrente dos transtornos mentais, e sua consequente qualificação como índice de uma condição humana inferior, por parte também de quem a vivencia, é outro elemento que 
contribui para que o desenho do cuidado não privilegie o usuário como seu eixo, preserve a ideia de que os trantornos mentais graves evoluem quase que impreterivelmente para a deterioração e que o estigma ligado a elas se mantenha. Estudos, principalmente da última década, têm indicado, por exemplo, que a recuperação dos transtornos mentais não está única e diretamente ligada à presença ou ausência de sintomas e que guarda íntima relação com o modo como o sujeito lida com esses fenômenos e os significa em suas vidas (CORIN; LAUZON, 1992; HONIG et al., 1998; ROMME; ESCHER, 1997; CORIN, 2003; DAVIDSON, 2003; DEL BARRIO et al., 2004).

Este panorama permite antever as dificuldades em jogo quando se trata de pôr em diálogo a perspectiva dos profissionais referidos ao modelo biomédico de conhecimento, em especial a do psiquiatra, aparelhado com o instrumental dos sistemas classificatórios que só acessam a esquizofrenia do exterior, e a da pessoa com diagnóstico de esquizofrenia, que vivencia uma transformação nos aspectos mais básicos de suas modalidades experienciais. Consegue o psiquiatra, e os demais profissionais que utilizam modelos que compartilham características semelhantes ao modelo de conhecimento biomédico, acessar esta experiência e compreender as narrativas produzidas pelos usuários a partir dela? E o usuário com diagnóstico de esquizofrenia consegue compreender melhor sua experiência de adoecimento e dar sentido ao seu processo de tratamento, a partir da imagem de seu transtorno oferecida pela psicopatologia descritiva e seus sistemas classificatórios? Não seria chegada a hora de investir na radicalização do diálogo entre as perspectivas do usuário e do psiquiatra, trazendo para o centro da cena aquilo que deve ser o objeto da Psicopatologia: a experiência subjetiva corporificada e as elaborações narrativas engendradas a partir dela?

O presente estudo, realizado em parceria entre a Universidade Federal do Rio de Janeiro (UFRJ), a Universidade Estadual de Campinas (UNICAMP) e a Universidade Federal da Bahia (UFBA), pretendeu conhecer a experiência das pessoas com o diagnóstico de transtorno do espectro esquizofrênico, em tratamento nos Centros de Atenção Psicossocial (CAPS), e a experiência dos psiquiatras inseridos na rede pública de atenção à saúde mental. Narrativas relacionadas ao processo saúde-doença, no caso de pessoas com diagnóstico de esquizofrenia, e narrativas sobre o processo de formulação do diagnóstico de esquizofrenia, prognóstico e tratamento, no caso dos psiquiatras, foram 
estudadas. Investigar se as narrativas sobre a experiência de adoecimento dos usuários iluminam o conhecimento técnico do psiquiatra e se o conhecimento técnico dos psiquiatras é capaz de iluminar a experiência dos usuários sobre o fenômeno saúde-doença-cuidado foram os principais objetivos deste estudo. ${ }^{1}$

\section{Método}

Este é um estudo qualitativo, multicêntrico, informado pelas abordagens teóricas da Análise Interpretativa Fenomenológica (SMITH; FLOWERS; LARKIN, 2009) e da Antropologia médica (KLEINMAN; EISENBERG; GOOD, 1978; KLEINMAN, 1988; GOOD, 1994), realizado nas cidades de Campinas, Rio de Janeiro e Salvador. Nele foram analisadas narrativas de experiência de adoecimentos de usuários de CAPS diagnosticados com esquizofrenia e narrativas acerca do processo de formulação do diagnóstico e tratamento de pessoas com o diagnóstico de esquizofrenia de psiquiatras inseridos na rede pública de atenção à saúde mental.

A Análise Interpretativa Fenomenológica é um tipo de abordagem aplicada à pesquisa qualitativa que, orientada pelo referencial teórico da Fenomenologia e Hermenêutica, visa compreender de modo interpretativo os processos de construção de sentido, o universo de significações, açôes sociais e relações entre os sujeitos, situados em determinado contexto e momento histórico e o modo como estes compartilham a própria experiência e seus significados (SMITH; FLOWERS; LARKIN, 2009).

A experiência de adoecimento relaciona-se ao modo como a pessoa que adoece, seus familiares e sua rede social vivem, interpretam, explicam, lidam e respondem ao sofrimento causado por uma doença. Nesta perspectiva, as narrativas sobre o adoecimento ocupam posição de suma relevância nos estudos sobre a experiência do adoecimento (KLEINMAN, 1988), supondo o entrelaçamento entre subjetividade, corpo, linguagem e cultura (SCHUTZ, 1945; GOOD, 1994; DAVIDSON, 2003). As narrativas exercem a função de mediação entre a experiência vivida dos sujeitos imersos em uma comunidade linguística e os acontecimentos e a unidade temporal da história relatada (RICOEUR, 1997). Sua análise vem sendo crescentemente utilizada nos estudos qualitativos em saúde como estratégia para acessar a experiência subjetiva e as biografias dos participantes (ONOCKO CAMPOS; FURTADO, 2008; RABELO; ALVES; SOUSA, 1999). 
A principal ferramenta metodológica empregada para produção das narrativas foram os grupos focais (KRUGER; CASEY, 2009). Técnicas da entrevista de explicitação (VERMERSCH, 2006), que orientam a formulação de questôes que evitam narrativas generalizantes, distantes da sua vivência pessoal, foram incorporadas. Escolheu-se o grupo focal também porque, no caso dos usuários, se tratava de uma população com menor poder contratual, que dispóe de um conhecimento sobre a própria experiência que não é a priori legitimado socialmente. O setting grupal tem a capacidade de criar ambiente de suporte mútuo e de reasseguramento entre os participantes, proporcionando maior fluidez no processo de construção das narrativas e minimizando a verticalidade que geralmente existe entre pesquisador e participante em situação de entrevista individual (MOEKE-MAXWELL; WELLS; MELLSOP, 2008).

O processo de recrutamento dos participantes aconteceu de agosto a novembro de 2009. Os sujeitos da pesquisa foram usuários de um CAPS em cada uma das localidades e psiquiatras de Campinas e do Rio de Janeiro. Dentre os que aceitaram participar da pesquisa, foram recrutados os que contemplaram os critérios abaixo indentificados:

Usuários: 1) autoatribuição de experiências comuns à condição esquizofrênica (alteração da consciência de si, audição de vozes, sensação de estar sendo perseguido ou vigiado, entre outras). Para favorecer a autoatribuição de experiências, foi exibido um vídeo, seguido de uma roda de conversa com os usuários dos serviços. Nesse momento, os usuários se identificavam ou não com as modalidades experienciais relacionadas à esquizofrenia, apresentadas no vídeo. $\mathrm{O}$ vídeo, produzido pela equipe de pesquisa com o patrocínio da FAPERJ, em parceria com alunos da Escola de Comunicação da UFRJ, reuniu autorrelatos de pessoas com o diagnóstico de esquizofrenia selecionados a partir de levantamento bibliográfico na secção de First-Person Accounts do Schizophrenia Bulletin, no período de 1980 a 2009. Os autorrelatos foram adaptados, roteirizados e atuados por atores amadores. Para a elaboração do roteiro, levou-se em conta tanto o espectro de experiências peculiares ao adoecimento esquizofrênico quanto o perfil sócio-demográfico da clientela dos CAPS do Rio de Janeiro; 2) ter o diagnóstico de esquizofrenia ou transtorno psicótico, segundo o instrumento diagnóstico MINIPLUS e o diagnóstico da equipe, ambos orientados pelos critérios da CID10; e 3) estar em tratamento no CAPS e não haver contra indicação, por parte da equipe, à sua participação. 
Psiquiatras: trabalhar na rede pública de saúde mental, em serviço diferente do serviço em que foram recrutados os usuários, a fim de se preservar o vínculo e a privacidade envolvidos na relação médico-paciente.

No decorrer do processo de recrutamento, alguns usuários, apesar de terem preenchido os critérios e concordado em participar do estudo, não compareceram aos grupos. No caso dos psiquiatras, as principais barreiras a impossibilitar ou dificutar o recrutamento e sua participação foram: sobrecarga de trabalho, alta rotatividade destes profissionais nos serviços, escassez desta categoria profissional na rede de saúde mental, dificultando seu afastamento para realizar atividades além das previstas, dentre outros. Em Salvador, por estes motivos, não foi possível realizar o grupo com psiquiatras.

Os grupos focais, audiogravados e transcritos, foram conduzidos por dois a três pesquisadores (moderador, observador e anotador). No caso dos grupos focais com usuários, um técnico do serviço participou exercendo a função de moderação clínica. Os grupos aconteceram de novembro de 2009 a setembro de 2010, nos próprios serviços, em três tempos. No tempo 1 (T1), os usuários recrutados em cada uma das cidades se reuniram com o propósito de produzir narrativas sobre o processo de adoecimento e os psiquiatras se agruparam para narrar a experiência de construção do diagnóstico e do projeto terapêutico. Os temas propostos nos grupos com os usuários foram: antecedentes, crise, restabelecimento (recovery)/não-restabelecimento. Para a discussão destes temas, 22 encontros aconteceram nas três cidades. Nos grupos com psiquiatras, foram discutidos: formulação do diagnóstico de esquizofrenia, prognóstico e tratamento. Foram realizados dois encontros, pelas limitaçōes acima descritas. No tempo 2 (T2), os usuários de cada um dos serviços se reuniram para discutir as narrativas dos psiquiatras, apresentada em texto transcrito, e vice-versa. Nesta fase, foram realizados sete encontros com usuários, nas três cidades, e dois com psiquiatras. No tempo 3 (T3), realizado apenas no Rio e em Campinas, usuários e psiquiatras se encontraram presencialmente no mesmo grupo com o propósito de discutir o material produzido em todo o processo. Nesta última fase, dois encontros foram realizados. O número de participantes nos grupos focais foi de sete usuários no Rio de Janeiro, quatro em Campinas e sete em Salvador. O participantes psiquiatras foram quatro do Rio de Janeiro e cinco em Campinas. Técnicas da observação participante (no processo de entrada no campo e 
recrutamento e nos grupos), registros de campo e entrevistas (diagnósticas) individuais também fora utilizados.

$\mathrm{O}$ processo de análise das informações aconteceu em três momentos distintos. Primeiramente, dois pesquisadores codificaram e categorizaram, de forma independente, os textos das transcriçôes, à luz de árvores de análise estruturadas a partir dos eixos temáticos propostos nos grupos. $\mathrm{O}$ contato com o material permitiu a identificação de diferentes modalidades narrativas: modelo explicativo, descrição da experiência e impacto da experiência/experiência encarnada. Daí emergiram também categorias e subcategorias temáticas: experiência de adoecimento; diagnóstico de esquizofrenia; estigma social; experiência de restabelecimento; tratamento e contexto dinâmico dos CAPS. Após este primeiro momento, os mesmos pesquisadores validaram conjuntamente as categorizações prévias e geraram a primeira versão categorizada e consolidada do material, a partir da inserção das narrativas em uma máscara de análise. Finalmente, um terceiro pesquisador trabalhou na validação final do material, gerando uma versão mais sintética das narrativas, de acordo com as categorias e subcategorias temáticas.

A pesquisa foi realizada segundo as normas e princípios éticos de pesquisas envolvendo seres humanos, com parecer aprovado pelos Comitês de Ética e Pesquisa do Instituto de Psiquiatria da UFRJ (no 87 Liv. 02-09), do Comité de Ética da UNICAMP (no 870/2009) e da Secretaria Municipal de Saúde do Rio de Janeiro (no 210A/2009). Todos os participantes foram esclarecidos acerca dos objetivos e procedimentos do estudo e forneceram consentimento informado para participar, mediante assinatura do Termo de Consentimento Livre e Esclarecido. Os nomes que identificam os participantes são fictícios, a fim de preservar seu anonimato.

\section{Resultados: o que mostram as narrativas}

As narrativas analisadas e apresentadas neste artigo foram produzidas com a participação de 18 usuários e nove psiquiatras, que têm suas principais características sociodemográficas indicadas nas tabelas 1 e 2.

A média de idade dos usuários é 44 anos, sendo a maioria do sexo masculino, solteira, em idade produtiva, com ensino médio completo, não inserida no mundo do trabalho, identifica-se como miscigenada e refere ter religião. A média de idade dos psiquiatras foi 32 anos. Todos são formados em universidades públicas e descrevem-se como brancos. A maioria é do sexo feminino e tem dois ou mais empregos. Dois referem ter pós-graduação senso estrito. 

de Janeiro e Salvador, 2009-2010

\begin{tabular}{|c|c|c|}
\hline Variáveis & & $\mathrm{N}(18)$ \\
\hline \multirow[t]{4}{*}{ Sexo } & Feminino & 6 \\
\hline & Masculino & 12 \\
\hline & 30-39 anos & 5 \\
\hline & 40-49 anos & 8 \\
\hline \multirow[t]{4}{*}{ Faixa etária } & 50-59 anos & 1 \\
\hline & 60-69 anos & 3 \\
\hline & Sem informação & 1 \\
\hline & Solteiro (a) & 10 \\
\hline \multirow[t]{4}{*}{ Estado civil } & Casado(a)/amigada(o) & 6 \\
\hline & Divorciado (a)/separado(a) & 2 \\
\hline & Ensino fundamental incompleto & 4 \\
\hline & Ensino fundamental completo & 2 \\
\hline \multirow[t]{5}{*}{ Escolaridade } & Ensino médio incompleto & 1 \\
\hline & Ensino médio completo & 9 \\
\hline & Ensino superior completo & 1 \\
\hline & Sem informação & 1 \\
\hline & Negra & 5 \\
\hline \multirow[t]{2}{*}{ Raça/Etnia } & Parda & 6 \\
\hline & Branca & 7 \\
\hline \multirow[t]{3}{*}{ Profissão/ocupação } & Desempregado & 6 \\
\hline & Aposentado/Auxílio doença/Pensionista & 11 \\
\hline & Sem informação & 1 \\
\hline \multirow[t]{6}{*}{ Religião } & Católica & 7 \\
\hline & Evangélica & 4 \\
\hline & Espírita & 2 \\
\hline & Não tem & 2 \\
\hline & Outras & 2 \\
\hline & Sem informação & 1 \\
\hline Diagnóstico (segundo & Transtorno Psicótico & 2 \\
\hline o MINIPLUS) & Esquizofrenia & 16 \\
\hline
\end{tabular}



e Rio de Janeiro. 2009-2010

\begin{tabular}{lcc}
\hline Variáveis & & N (9) \\
\hline Sexo & Feminino & 6 \\
& Masculino & 3 \\
\hline Faixa etária & $20-29$ anos & 2 \\
& $30-39$ anos & 7 \\
\hline Escolaridade & Ensino superior completo & 7 \\
& em universidade pública & \\
\hline Raça/Etnia & Pós-graduação & 2 \\
\hline Vínculo de trabalho na rede & Branca & 9 \\
pública de saúde mental & & 3 \\
& 2 & 4 \\
\hline
\end{tabular}

*Valor de referência $\mathrm{R} \$ 622,00$

\section{Análise das narrativas}

As categorias identificadas neste estudo e as narrativas que as compuseram serão apresentadas a seguir. A discussão tem o propósito de dar visibilidade aos elementos que caracterizam as narrativas-experiências dos parcipantes e indicar o modo como se configura sua complexidade.

\section{A Experiência de Adoecimento}

Eu vivi a minha vida toda sendo diferente, não porque eu me achava diferente, era o externo que me achava diferente. (Sônia).

A vivência do transtorno mental - expressa no fragmento acima através da fala sobre ser diferente, uma alteração do sentimento de si-nem sempre é identificada como adoecimento, podendo se apresentar como uma experiência de vida, uma marca de existência. 
Quando a gente não tá bem a gente não tem percepção que as coisas estão indo mal pra gente. Quem percebe sempre é um membro da família [...]. (Carlos).

Nas circunstâncias em que alterações psicopatológicas são vivenciadas como marca existencial e de vida, e não de adoecimento, como mostram os fragmentos acima, a vivência de adoecimento pode advir mesmo assim, precipitada pelo olhar e/ou pela palavra do outro, de fora para dentro. A experiência de adoecimento pode ainda surgir em decorrência de consequências negativas ocasionadas na vida da pessoa, como observado na narrativa seguinte:

Eu fui suspensa e com a suspensão eu fiquei muitíssimo abalada, fiquei com depressão, muito magrinha... (Regina).

Este fragmento evidencia que o sofrimento, o sentimento de estar adoecido, foi experimentado a partir da suspensão do trabalho, foi efeito desta suspensão e não das dificuldades que a antecederam; estas sim, provavelmente ligadas diretamente à doença e expressão de seus sintomas. A experiência de adoecimento, neste e no exemplo anterior, não é consequência direta das alterações propriamente ditas do transtorno mental. É sim um resultado indireto delas, já que estas alterações não são vivenciadas nem reconhecidas como problemas por quem as experiencia. No exemplo da Regina, todavia, a experiência de adoecimento não surge de fora para dentro, do jogo relacional, como efeito de um olhar ou palavra do outro. Aqui, a vivência de adoecimento decorre da repercussão, sobre a vida da pessoa, daquilo que externamente se reconhece como um sintoma ou como alteração psicopatológica.

O corpo está sempre presente nas experiências de adoecimento relatadas. Varia a forma de apresentação. Em relatos de experiência da crise, por exemplo, o corpo se presentifica a partir da vivência de uma ruptura radical que provoca uma alteração na familiaridade básica que envolve a relação com o corpo:

Me sentia normal [...] [com a crise]... você perde os cinco sentidos, os cinco sentidos vão pra falência. (César).

Sensações desagradáveis no corpo são referidas muitas vezes:

A gente sente uma dor sem ter nada, sem ter machucadura nenhuma. (Sonia).

As manifestações corporais também podem aparecer na construção da experiência de adoecimento, fundamentando uma teoria explicativa:

Eu acho que é por força de uma desnutrição. Algum tipo de vitamina, proteína que me deixava com essa variação na ideia. (Saulo). 
A inércia é relatada como importante ou mesmo principal sinal de adoecimento. Fala-se muito da necessidade de movimento, de empreender alguma atividade que faça o corpo se mexer:

Tem que brigar consigo mesmo, brigar com a doença, pra não ficar assim jogada, né. (Selma).

\section{O Diagnóstico de Esquizofrenia}

Eu perguntei: “Doutor, eu tenho o quê?!”. Ele disse: "Você é esquizofrênico”. (Silvio).

Nem sempre a forma de tomar contato com o diagnóstico é assim, pela via da comunicação direta entre médico e paciente, como observado no diálogo a seguir:

- Cleusa: Esquizofrenia .... Eu queria saber o significado disso.

- Moderador: .... Já disseram isso para a senhora? De esquizofrenia, já falaram isso para a senhora?

- Cleusa: Não falam!... Eu tenho uma carta plastificada, que eu tenho que andar com ela.

- Moderador: E está escrito esse nome lá?

- Cleusa: Tá...

Que sentido pode ter esta palavra, este diagnóstico, para um usuário de serviços de saúde mental? Em que isto o ajuda a compreender as inusitadas vivências subjetivas que o acompanham, em alguns casos há muito tempo? Qual a relação deste nome com suas experiências de vida e com o percurso de tratamento que muitas vezes ele inaugura? Seja através da comunicação direta do diagnóstico, seja pela sua presença escrita em algum laudo ou documento, a etiqueta diagnóstica parece pouco servir para responder às inquietações que estas perguntas carregam.

Até hoje o médico não definiu. A primeira coisa que o médico falou para mim, falou que eu estava com esquizofrenia. E o outro médico falou que eu estava com distúrbio mental. E o outro falou que eu estava doente mental. Eu tomo vários tipos de medicamentos! E depois o médico falou que depois de dois anos, eu poderia parar de tomar os remédios, que eu ia ficar bom. Por que eu estou assim até hoje? Tem alguma coisa [...] invisível. (Rui)

As várias formas utilizadas pelos profissionais de saúde para nomear os problemas mentais, reflexo de modelos classificatórios diversos, ou mesmo de diferentes estratos de um mesmo sistema classificatório, são frequentemente 
experimentadas pelos usuários como indefinição do seu problema, dificultando

o manejo com o próprio problema, com os tratamentos e vivido como índice de um prognóstico nebuloso, não palpavél e pouco compreensível.

Da perspectiva dos psiquiatras, o diagnóstico, no contexto da prática clínica nos CAPS, tem importância pragmática relativa e tende a ter deflacionada a sua relevância para esta prática clínica. $\mathrm{O}$ diagnóstico parece ajudar pouco o psiquiatra a dar a direção do tratamento, e é experimentado como recurso insuficiente para definir as estratégias terapêuticas a serem utilizados no contexto do CAPS. A função do diagnóstico foi delimitar um certo campo de problemas:

Eu só não acho que os dispositivos que eu vou usar sejam tão diferentes se fosse um outro diagnóstico. A forma de pensar, a forma de você cuidar vai ser a mesma, independe do diagnóstico [...]. Eu acho que o diagnóstico não é pra eu saber como eu vou tratar, é pra eu saber em que área que eu estou caminhando, entendeu? (Roseana).

As narrativas dos psiquiatras sobre o processo de feitura do diagnóstico revelam uma mescla de aspectos objetivos e subjetivos ou empáticos. Os objetivos se aproximam dos critérios operacionais dos sistemas classificatórios vigentes:

[...] Quando dá crise é bem fácil. Você tem os sintomas, são floridos, né, as alucinações, delírios de influência... (Cleber).

Os elementos oriundos de uma apreensão subjetiva, empática, por sua vez, encontram pouca ou nenhuma ressonância nos critérios operacionais destes sistemas classificatórios e na psicopatologia descritiva. Os psiquiatras indicam encontrar no senso comum o sentido para os aspectos subjetivos e empáticos que se presentificam no processo de feitura do diagnóstico. Observa-se, entretanto, como é próprio aos sentidos que emergem do senso comum, que são sentidos pouco refletidos e, por isso, frequentemente naturalizados:

Eu tendo a achar que é uma coisa muito sutil assim sabe? É uma coisa que foge [...] é uma coisa realmente mais subjetiva, que às vezes está num certo estar do indivíduo, no seu contexto de vida. (Roseana).

Outro traço comum encontrado nas narrativas dos psiquiatras diz respeito a associação entre o diagnóstico de esquizofrenia e a expectativa de um prognóstico necessariamente desfavorável, o que os leva muitas vezes a evitar e/ou adiar a formulação do diagnóstico e a sua posterior comunicação aos pacientes e aos seus familiares:

É, tem que ter um cuidado né, pra dar o diagnóstico! (Carmen) 
Estou pensando em alguns pacientes em que a dúvida persistiu...Acho que aí tem uma torcida para que não seja isso... Esquizofrenia não!! Eu acho que a gente torce para que não seja isso! (Carol).

Nas narrativas dos usuários, a contrapartida destas preocupações se revela através do peso estigmatizante que experimentam quando o diagnóstico de esquizofrenia lhes é atribuido, direta ou indiretamente. Os usuários desconhecem os critérios em jogo na atribuição deste diagnóstico, por parte do psiquiatra, e desconhecem também os sentidos que o médico lhe atribui. Tais sentidos são praticamente incompreendidos para quem os recebe, além de pouco evidentes. A força estigmatizante do diagnóstico é o que se manifesta com pujança para os usuários, conforme observado nos relatos a seguir:

Esquizofrênico... De onde ele tirou essa palavra?! [...] Um rótulo muito forte, machuca muito uma pessoa, entende?! (Rogério).

Dependendo do paciente, o diagnóstico, eu acho que pode não ser escondido, mas pode ser omitido, para o bem do próprio paciente. Até ele adquirir uma maturidade maior para ele entender exatamente o que ele tem, ou que ele possa entender só o que convém para ele entender, devido à sua problemática. (Raílson).

Nas narrativas estudadas, a força estigmatizante promove a recusa ou a evitação do diagnóstico. Alguns usuários sugerem que ele só seja revelado numa perspectiva dialógica, de modo que quem o receba possa elaborar seu sentido.

\section{Estigma Social}

A temática do estigma ligado aos transtornos mentais, em particular à esquizofrenia, se apresenta tanto na narrativa dos psiquiatras, quanto na dos usuários. Para os psiquiatras, em geral, o estigma se revela ligado ao tema do diagnóstico de esquizofrenia, expresso na cautelosa formulação do diagnóstico e de sua comunicação, como já indicado acima:

Eu sinto que muitas vezes eu resisto [a atribuir o diagnóstico de esquizofrenia]! (Carol).

No relato dos usuários, o tema do estigma se relaciona diretamente à experiência de adoecimento e liga-se também aos efeitos do adoecimento sobre sua vida, àquilo que ele ou os outros supõem que possa ou não fazer. $\mathrm{O}$ modo como a sociedade os vê e valora, elemento determinante da experiência do estigma, pode ser experimentado, por exemplo, como um das consequências da crise:

Quando eu voltei da crise, hoje em dia todo mundo me trata diferente, ninguém con-

fia em você como confiava antes [...]. Ó, minha mãe é bem difícil ela me deixar andar 
sozinho [...]. A confiança deles, da minha tia, eu não recuperei até hoje. É difícil eles

confiarem em mim (Ricardo).

$\mathrm{Na}$ experiência de alguns usuários, o estigma começa dentro da própria família, estendendo-se à vizinhança/comunidade e ao mundo do trabalho:

O preconceito é grande, o mercado de trabalho não aceita pessoas com esquizofrenia, têm medo de a pessoa ter uma crise mais violenta. (Sônia).

O estigma internalizado, uma outra forma de experimentar o estigma, está fortemente presente e é igualmente fonte de sofrimento, como relata Roberta:

Eu queria ser diferente, mas eu fiquei diferente de outra forma [...]. É muito difícil você aceitar que você é doente. Você ver que um dia você foi boa e agora é doente.

Para alguns usuários, a superação do estigma é possível, a despeito de sua força, e pode ser uma das vias do restabelecimento.

\section{A Experiência de Restabelecimento}

A complexidade do processo de restabelecimento, entendido aqui como dimensão da experiência de adoecimento, tem relação com o estigma social:

$\mathrm{Na}$ minha rua eu fiquei tachada como louca, que eu moro num bairro onde meus vizinhos pararam de falar comigo quando eu fui internada no hospital psiquiátrico [...]. Então quando você sai, você escuta: “Cuidado é maluca, maluca!”A gente fica taxada para o resto da sua vida... (Regina).

Para os usuários, o restabelecimento constitui um processo que se dá no fluxo da experiência. Vivido como um mosaico de possibilidades, pode envolver a melhora ou piora dos sintomas, o restabelecimento parcial ou superação da doença, e ainda o enfrentamento do estigma social. O restabelecimento foi experimentado também a partir do manejo dos efeitos e dificuldades que decorrem do adoecimento, principalmente àqueles relacionados às atividades $\mathrm{da}$ vida diária e inserção no mundo do trabalho. Vale ressaltar que nem sempre os usuários reconhecem essas dificuldades como adoecimento.

Depois da crise?! Ah, fiquei impossibilitado para muita coisa... Eu sempre sonhei, assim, eu estava estudando na época, trabalhando, sempre sonhei em fazer uma carreira [...]. Então a médica falou que eu não podia mais trabalhar [...], então aquilo ali me impossibilitou [...], aí eu fiquei nessa dúvida: o quê mais eu posso fazer?! ( Ricardo).

A aceitação da doença e do tratamento e a superação da etiqueta diagnóstica também foram aspectos relevantes para o restabelecimento, nas narrativas 
dos usuários. Observa-se, entretanto, que estes três aspectos não descrevem as mesmas experiências: aceitação da doença não é o mesmo que aceitação da etiqueta diagnóstica, ou do tratamento, e superação não necessariamente passa pela aceitação da etiqueta diagnóstica. A etiqueta diagnóstica, por exemplo, pode ser recusada e, ao mesmo tempo, o tratamento ser aceito. Rogério mostra isso de forma clara quando diz que não vai "carregar [...] esse rótulo" e "vai passar uma borracha nisso tudo", ao referir-se ao diagnóstico de esquizofrenia. Ele, todavia, é assíduo ao CAPS e utiliza os tratamentos ali ofertados. Os relatos indicam ainda que a aceitação da doença não necessariamente signfica aceitar a descrição desse fenômeno em termos biomédicos ou psicológicos ou fazendo uso desses vocabulários. A aceitação da doença, de modo a promover o restabelecimento, pode ocorrer mediado por outros sentidos.

Usuários que experimentam como problemas de saúde mental o que os psiquiatras descrevem como sintomas - "vozes", "depressão", "momentos de delírio" - podem encontrar "melhora" e "controle" dessas vivências, mediante tratamento, e assim experimentar, em alguma medida, o restabelecimento. A busca de explicação sobre os motivos que os levaram a entrar em crise ou a piorarem novamente é um esforço de atribuição de sentido à experiência de estar adoecido. Esse exercício constitui outra via para o restabelecimento, podendo ser utilizada por aqueles que vivenciam ou não "melhora" ou "controle" dos seus problemas, conforme faz Cleusa no próximo fragmento:

Eu queria saber assim, também, porque tem hora que eu fico boa, ai daqui um pouco que já vou começar tudo de novo?

A criação de estratégias pessoais em busca do restabelecimento frequentemente vão além do âmbito do tratamento no CAPS, como referiu um dos usuários que se valeu da estratégia religiosa de "tomar passe magnético". As narrativas dos usuários mostram também que os recursos terapêuticos ofertados pelo serviço e pelo sistema de saúde podem ser ressignificados. Encontrar um sentido para o CAPS e para as práticas que aí se realizam, por parte dos usuários, pode acontecer mesmo quando estes sentidos são estranhos e distantes daqueles que os profissionais de saúde lhe atribuem. César exemplifica bem isso quando diz que vai ao CAPS porque lá se "desmancha trabalho". Repousar no quarto sozinho, "ir para a rua"; "ficar sentada no escuro"; "catar latinhas"; "entrar para a política"; não "dar confiança para as vozes" ou reconhecer "quando as vozes 
estão chegando", foram algumas estratégias peculiares utilizadas pelos usuários para lidar com o mal estar que experimentam.

O CAPS foi referido como parte do conjunto maior de recursos que contribui para o enfrentamento da experiência de adoecimento e para a criação de oportunidades de restabelecimento. As estratégias vinculadas ao contexto de tratamento no CAPS foram: "correr para o CAPS" em caso de sentir-se mal; "passar o dia no CAPS"; "tomar medicação"; "conversar"; "ocupar a mente" e observar outros usuários no convívio com o CAPS, como diz Sônia:

Eu fico observando esses pacientes, não porque quero cuidar da vida deles, mas pra saber de fato como é que eu fico quando estou em crise.

O restabelecimento pode ainda ser favorecido pela experiência de recuperação da capacidade de circular, de retomar um percurso no território e de retraçar um cotidiano no espaço habitado.

Eu me sinto muito bem, porque hoje eu pego ônibus e venho sozinha. Eu não pegava um ônibus. [...] eu não andava sozinha mais, você entende? Eu não descia o morro para ir na padaria. Hoje eu vou na padaria, hoje eu vou no mercado. (Roberta).

\section{Tratamento e o contexto dinâmico dos CAPS}

Os usuários referem que serviços comunitários de saúde mental tipo CAPS, e os hospitais psiquiátricos, propiciam experiências diferentes. A experiência de melhora após o início do tratamento no CAPS se dá mesmo com o relato de recidivas da crise e de outras manifestações da doença.

A medicação é descrita pelos usuários como um mal necessário, principalmente por seus efeitos no corpo. A tomada diária é vivida como dolorosa e produtora de sofrimento:

Eu tomo injeção e remédio sabe... muito remédio, remediada que eu tomo aí... [...] tomar um monte de agulhada, não é fácil não, agulhada não, dói...sofri, sofri... (Caio).

O uso dos medicamentos é considerada uma necessidade da qual não podem prescindir se querem encontrar algum tipo de estabilização:

Agora eu diminui de ficar ouvindo vozes, depois que a médica passou um medicamento de alto custo da série ouro, aí eu diminui de ouvir vozes [...] Agora eu estou ouvindo uma vozinha de vez em quando. Estou bem melhor. (Sílvio)

Nas narrativas dos psiquiatras, a medicação é um dos principais determinantes da estabilização. Nos quadros esquizofrênicos, consideram não só indispensável como torna-se critério diagnóstico. 
Um marcador informal pra gente é isso... a questão da necessidade da medicação. [...] Isso não está no CID mas a gente pensa, se a gente consegue tirar a medicação e ele consegue viver bem, ai a gente vai pensar "não é esquizofrênico!", a gente refaz o diagnóstico, a nossa cabeça funciona assim. (Carol)

A expectativa de que os usuários não acatem o esquema medicamentoso como prescrito, apareceu num dos relatos:

Mais de 50\%, eu acho que não toma exatamente o que eu passo, toma o que ele, o que ele lá determina, o equilíbrio que ele encontra, né e daí eu avalio...(Raimundo).

Revela-se aí um reconhecimento de que o usuário pode não seguir o que the é indicado, ou fazê-lo a seu modo, e que ao médico cabe avaliar o equilíbrio que advém dessa escolha. Há relato da dificuldade frente à recusa da medicação prescrita no momento da crise. Essa dificuldade, produtora de angústia para o psiquiatra, tem relação com perceber-se sem recursos para manejar situaçōes desta natureza e não ter ferramentas para, a partir da recusa, estabelecer relação empática com o paciente:

[...] a sensação que me dá, é que com cinco minutos de conversa meu arsenal de argumentos acabou, eu falei: “o que é que eu vou fazer?", tipo assim, não consigo acessar nada, não tenho criatividade nenhuma na hora, tamanha a angústia que é pra mim esse tipo de situação. (Roseana)

De um modo geral, o estímulo à aceitação da prescrição é relatado como algo que exige esforço grande do médico e expõe a necessidade da construção compartilhada dessa proposta de tratamento, tarefa mais facilmente desenvolvida no contexto do CAPS: "criar um vinculo melhor" (Clovis), para "tornar aquela intervenção mais delicada possivel" (Roseana), exigindo "uma fineza que é sempre com o paciente, não é sem ele, né, medicar não é sem ele, né, sem o paciente” (Rita), sendo por vezes necessário adiar uma intervenção: "esse manejo dá pra fazer em CAPS" (Carla).

Nas narrativas dos usuários se destacam as diferenças entre as experiências de prescrição e do uso dos medicamentos nos contextos do hospital e do CAPS. $\mathrm{Na}$ internação psiquiátrica, a medicação é experimentada como imposta e não negociada. No CAPS, o fato de a medicação ser parte de uma gama mais ampla de ofertas e ser adminstrada num contexto em que o controle sobre a ingesta é menor, sua indicação e uso não são experimentadas como imposição arbitrária:

No sanatório você é obrigado a tomar medicação, você não tem querer. No CAPS, você pega o medicamento leva pra casa, tem o domínio, o controle. (Saulo). 
A medicação é referida pelos usuários como mais um dos elementos que concorre para a recuperação:

O remédio, as oficinas, a companhia da senhora, dos amigos, batendo papo, os passeios. (Silvio).

Muitos usuários falaram sobre o CAPS como um serviço que oferece diversas possibilidades terapêuticas, onde se pode "conversar", "fazer amigos", "fazer oficina”, "almoçar", "pegar remédio”, dentre outras atividades.

Eu acho que o tratamento no CAPS foi fundamental pra minha reabilitação, minha tentativa de me reabilitar, estabelecer meu sistema nervoso na tranquilidade. Eu venho, participo das oficinas, das atividades. Escutando as palestras e orientações que servem pra minha vida, pro meu dia a dia.[...] Eu não tô sentindo mais nada. Tô me sentindo mais tranquilo. (Saulo).

\section{Conclusão}

Distintas dimensões do mundo da vida se interconectam e tecem uma rede de experiências, ações, relações, lugares e significados. Tudo isso compõe, num sentido mais amplo, um campo que a antropologia médica nomeia como experiência de adoecimento (KLEINMAN; EISENBERG; GOOD, 1978; KLEINMAN, 1988; GOOD, 1994). Muitos elementos podem se articular nesta malha: o vivido subjetivo corporificado, o reconhecimento individual de que algo não vai bem, a convivência com a família e vizinhos, o trabalho, o cuidado em saúde mental, as dificuldades encontradas para integração na vida comunitária, estratégias utilizadas para superação, dentre outros elementos. Os resultados revelaram, todavia, que a experiência de adoecimento tout court se produz mesmo quando o usuário não experimenta como patológico aquilo que o psiquiatra identifica como sintoma. Para os usuários, a experiência de que algo vai mal e de que é patológico pode decorrer dos efeitos, sobre o cotidiano, daquilo que o psiquiatra chama de patológico. Algumas vezes é de fora para dentro, por ação ou olhar de um outro, por uma intervenção médica, ou mesmo pelo estigma que a vivência de adoecimento surge para o usuário. As estratégias e caminhos trilhados em direção ao processo de restabelecimento e superação também são multiplos e diversos (DAVIDSON, 2003). O processo de restabelecimento não depende exclusivamente dos recursos terapêuticos e ocorre, por exemplo, através da ressignificação da experiência do tratamento a partir de universos de sentido fora do campo da saúde. Isso tem 
grande importância no contexto brasileiro porque aqui o peso social negativo da esquizofrenia está na comunidade, no usuário e até mesmo na perspectiva do psiquiatra. O estigma, que pode mesmo estar internalizado, nem sempre é obstáculo ao processo de restabelecimento e este último não necessariamente requer o desaparecimento dos sintomas para ser vivenciado.

Quanto à experiência do processo de formulação do diagnóstico, do prognóstico e do projeto terapêutico, vivida pelos psiquiatras, as narrativas explicitam que o exercício clínico é marcado de forma especial e particular pela relação prática que se estabelece entre o conhecimento empiríco - aquele que emerge do exercício da formulação do diagnóstico, da indicação do tratamento e do encontro com a pessoa adoecida - e o conhecimento teórico, prévio a esse exercício prático. Dentre os vários aspectos que caracterizam o exercício clínico, dois se destacam. É um exercício solitário, não só porque o psiquiatra pode realizálo ou, em geral, o realiza sozinho, mas especialmente porque a experiência que vivencia neste exercício tem uma dimensão não compartilhável que não ecoa seus conhecimentos teóricos. O senso comum, principal saber a configurar a lente utilizada para conhecer a complexidade existencial da pessoa com transtorno mental, não encontra quaisquer elementos, no âmbito do conhecimento teórico adquirido previamente, que favoreçam seu questionamento, porque este é quase que exclusivamente marcado por uma visão naturalizada do sujeito.

Assim fica patente como a objetificação do transtorno mental, efeito do modo de construção diagnóstica proposto pelos sistemas de classificação empregados, que se limitam a uma Psicopatologia Descritiva, não fornece aos psiquiatras os recursos necessários para lidar com a diversidade de experiências existenciais subsumidas pela categoria "esquizofrenia". Reciprocamente, da perspectiva dos usuários, esta mesma objetificação do transtorno não os favorece em nada porque não lhes permite, a partir do vocabulário do médico e da equipe em geral, criar versões para sua experiência que sejam mais auspiciosas. Quando conseguem criar estas versões - seja através da adaptação do vocabulário do campo da saúde, ou lançando mão de algum outro - tais versões são pouco valorizadas pelos psiquiatras que não as considera significativas nem com sentidos relevantes, permanecendo como um desafio para o cuidado oferecido nos serviços tipo CAPS (BEZERRA, 2007; MENEZES; YASUI, 2009). Vale ressaltar, entretanto, que os CAPS apresentam-se como espaços potentes para a criação de pontes de diálogo entre as narrativas de usuários e psiquiatras e novos sentidos para o adoecer. 
O dispositivo metodológico proposto pela pesquisa, descrito acima na seção "Metodologia", visava criar condições favoráveis para a produção de narrativas por usuários de serviços de saúde mental e por psiquiatras. A apresentação recíproca das narrativas de cada um dos dois grupos foi feita no T2 dos grupos focais e no T3, quando ambos os grupos de participantes foram reunidos em um mesmo encontro de grupo focal. Tivemos como resultado uma rica produção narrativa, que é tomada como objeto de análise na seção "Resultados". Contudo, a conversa entre a experiência do psiquiatra e a experiência do usuário, que poderia ter sido suscitada no T2 e T3 dos grupos focais, efetivamente não acontece. Não é produzido nem um novo saber que seja útil para o psiquiatra, nem uma descrição que permita ao usuário lidar com a experiência do adoecimento. Nenhum novo saber sobre o vivido, que seja compartilhável, útil para os dois e para o campo da saúde mental, se produz a partir deste diálogo entre a experiência do psiquiatra e do usuário. As construções narrativas dos usuários parecem não produzir efeitos sobre as construções narrativas dos psiquiatras e vice-versa. Não foi possível identificar nenhuma narrativa híbrida, que incorpore elementos das narrativas dos usuários ou psiquiatras como algo que amplia o campo de conhecimento ou de ação. Permanece em aberto a questão acerca dos meios e recursos necessários para a produção de um conhecimento e de práticas que possam integrar as diferentes perspectivas em jogo. ${ }^{2}$

\section{Referências}

ALVERGA, A.R.; DIMENSTEIN, M. A reforma psiquiátrica e os desafios na desinstitucionalização da loucura. Interface, Botucatu, v. 10, n. 20, p. 299-316, 2006.

BEZERRA JR., B. Desafios da Reforma Psiquiátrica no Brasil. Physis, Rio de Janeiro, v. 17, n. 2, p. 243-250, 2007.

BRASIL. MINISTÉRIO DA SAÚDE. Portaria GM n 336, de 19 de fevereiro de 2002. Define e estabelece diretrizes para o funcionamento dos Centros de atenção Psicossocial. Diário Oficial da União, 2002; 20 de fev.

CORIN, E. L'Ombre de la Psychose... Des tracés en creux aux marges de la culture. Cahiers de Psychologie Clinique, v. 21, p. 197-218, 2003.

CORIN, E.; LAUZON, G. Positive Withdrawal and the Quest for meaning: The reconstruction of experience among schizophrenics. Psychiatry, v. 55, p. 266-278, 1992.

DAVIDSON, L. Living Outside Mental Illness. Qualitative studies of recovery in Schizophrenia. New York: New York University Press, 2003. 
DEL BARRIOS, L.R. et al. Avaliação qualitativa de Serviços em Saúde Mental a partir das perspectivas de usuários e profissionais. Negociação, cidadania e qualidade dos serviços. In: BOSI, M.L.M.; MERCADO, F.J.(orgs.) Pesquisa Qualitativa em Saúde. Petrópolis: Vozes, 2004. p. 401-450.

GOLDBERG, J. Clínica da Psicose. 2a ed. Rio de Janeiro: Te Corá, 1996.

GOOD, B. Medicine, rationality, and experience. Cambridge: Cambridge University Press, 1994.

HONIG, A. et al. Auditory Hallucinations: A Comparison between Patients and Nonpatients. Journal of Nervous and Mental Diseases, v. 186, n. 10, p. 646-651, 1998.

KLEINMAN, A. The Illness Narrative. Suffering, Healing and the Human Condition. New York: Basic Books, 1988.

KLEINMAN, A.; EISENBERG, L.; GOOD, B. Culture, Illness, and Care Clinical Lessons from Anthropologic and Cross-Cultural Research. Annals of Internal Medicine, v. 88, n. 2, p. 251-258, fev. 1978.

KRUGER, R.A.; CASEY, M.A. Focus Groups. A practical guide for applied research. $4^{\text {th }}$ ed. Thousand Oaks: Sage, 2009.

LEAL E.M.; DELGADO, P.G.G. Clínica e cotidiano: o CAPS como dispositivo de desinstitucionalização. In: PINHEIRO, R. et al. (orgs.). Desinstitucionalização na saúde mental: contribuiçôes para estudos avaliativos. Rio de Janeiro: Cepesc, 2007. p. 137-154.

LEAL, E.M.; SERPA JR., O.D.; MUÑOZ, N.M. A clínica da "disfunção social": contribuiçôes da psicopatologia do senso comum. In: COUTO, M.C.V.; MARTINEZ, R.G. (orgs.). Saúde Mental e Saúde Pública: Questôes para a agenda da Reforma Psiquiátrica. Rio de Janeiro: FUJB/NUPPSAM/IPUB/UFRJ, 2007, p. 69-99.

MENEZES, M.P.; YASUI, S. O psiquiatra na atenção psicossocial: entre o luto e a liberdade. Ciência \& Saúde Coletiva, v. 14, p. 217-226, 2009.

MOEKE-MAXWELL, T.; WELLS, D.; MELLSOP, G.W. Tangata whaiora/consumers perspectives on current psychiatric classification systems. International Journal of Mental Health Systems, p. 2-7, 2008.

ONOCKO CAMPOS, R.T. Clínica: a palavra negada - sobre as práticas clínicas nos serviços substitutivos de saúde mental. Saúde em debate, Rio de Janeiro, v. 25, n. 58, p. 98 111, maio/ago. 2001.

ONOCKO CAMPOS, R.T.; FURTADO, J.P. Narrativas: utilização na pesquisa qualitativa em saúde. Revista de Saúde Pública, v. 42, n. 6, p. 1.090-6, 2008.

RABELO, M.C.; ALVES, P.C.; SOUSA, I.M. Introdução. In: Experiência de Doença e Narrativa. Rio de Janeiro: Fiocruz, 1999.

RICOEUR, P. Tempo e narrativa. Campinas: Papirus, 1997. 
ROMME, M.; ESCHER, S. (orgs.) Na Companhia das Vozes. Para uma análise da experiência de ouvir vozes. Lisboa: Estampa, 1997.

SARACENO, B. Manual de saúde mental. 2 ed. São Paulo: Hucitec, 1997.

Libertando Identidades: da reabilitação psicossocial à cidadania possível. Rio de Janeiro: Instituto Franco Basaglia, 1999.

SCHUTZ, A. On multiple realities. Philosofy and Phenomenological Research, v. 5, n. 4, p. 533-576, 1945.

SERPA JR., O.D.; LEAL, E.M. Schizophrenia, Experience and Culture. Dialogues in Philosophy, Mental and Neuro Sciences, v. 3, n. 2, p. 50-51, 2010.

SERPA JR., O.D. et al. A inclusão da subjetividade no ensino da psicopatologia Interface. Comunicação, Saúde e Educação. Botucatu, v. 11, p. 207-222, 2007.

SMITH, J.A.; FLOWERS, P.; LARKIN, M. Interpretative Phenomenological Analysis: Theory, Method and Research. London: Sage, 2009.

TENÓRIO, F. A psicanálise e a clínica da Reforma Psiquiátrica. Rio de Janeiro: Rios Ambiciosos, 2001.

THORNICROFT, G.; TANSELLA, M. Quais são os argumentos a favor da atenção comunitária à saúde mental?. Pesquisas e Práticas Psicossociais. São João del-Rei,v. 3, n. 1, p. 9-25, 2008.

VERMERSCH, P. L'entretien d'explicitation. Paris: ESF, 2006.

\section{Notas}

${ }^{1}$ A pesquisa foi financiada pelo Conselho Nacional de Desenvolvimento Científico e Tecnológico (Edital MCT/CNPq/CTSaúde/MS/SCTIE/DECIT no 33/2008) e os autores declaram não haver conflito de interesses.

${ }^{2}$ O.D. Serpa Jr: coordenador geral da pesquisa e do campo "Rio de Janeiro". Elaboração do projeto de pesquisa. Participação em reuniões multicêntricas de pesquisa para construção, organização do campo empírico e ajustes metodológicos para os procedimentos de recrutamento e coleta de dados. Condução de grupos focais no Rio de Janeiro e Salvador. Participação em reuniōes multicêntricas para análise e interpretação dos dados. Participação na redação e revisão da versão final do artigo. R. Onocko-Campos: coordenadora do campo "Campinas". Elaboração do projeto de pesquisa. Participação em reuniōes multicêntricas de pesquisa para construção, organização do campo empírico e ajustes metodológicos para os procedimentos de recrutamento e coleta de dados. Participação em reuniōes multicêntricas para análise e interpretação dos dados. Participação na redação e revisão da versão final do artigo. N. Malajovich: elaboração do projeto de pesquisa. Participação em reuniōes multicêntricas de pesquisa para construção, organização do campo empírico e ajustes metodológicos para os procedimentos de recrutamento e coleta de dados. Condução de grupos focais no Rio de Janeiro. Participação em reuniões multicêntricas para análise e interpretação dos dados. Participação na redação e revisão da versão final do artigo. A.M. Pitta: coordenadora do campo "Salvador". Elaboração do projeto de pesquisa. Participação em reuniōes multicêntricas de pesquisa para construção, 
organização do campo empírico e ajustes metodológicos para os procedimentos de recrutamento e coleta de dados. Condução de grupos focais em Salvador. Participação em reunióes multicêntricas para análise e interpretação dos dados. Participação na redação e revisão da versão final do artigo. A.G. Diaz: implementação prática do campo "Campinas". Elaboração do projeto de pesquisa. Participação em reuniōes multicêntricas de pesquisa para construção, organização do campo empírico e ajustes metodológicos para os procedimentos de recrutamento e coleta de dados. Condução de grupos focais em Campinas. Participação em reuniōes multicêntricas para análise e interpretação dos dados. Revisão da versão final do artigo. C. Dahl: elaboração do projeto de pesquisa. Participação em reuniōes multicêntricas de pesquisa para construção, organização do campo empírico e ajustes metodológicos para os procedimentos de recrutamento e coleta de dados. Condução de grupos focais no Rio de Janeiro e Campinas. Participação em reuniões multicêntricas para análise e interpretação dos dados. Participação na redação e revisão da versão final do artigo. E. Leal: elaboração do projeto de pesquisa. Participação em reuniôes multicêntricas de pesquisa para construção, organização do campo empírico e ajustes metodológicos para os procedimentos de recrutamento e coleta de dados. Condução de grupos focais em Campinas e Salvador. Participação em reuniōes multicêntricas para análise e interpretação dos dados. Participação na redação e revisão da versão final do artigo. 
Experience, narrative and knowledge: the perspective of the psychiatrist and the user This study, conducted in a partnership composed by UFRJ, UNICAMP and UFBa, wanted to investigate the experience of people with a diagnosis of schizophrenia spectrum disorder, in treatment in CAPS, and the experience of psychiatrists inserted in the public mental health care services. Narratives related to health and illness, in the case of people with schizophrenia, and narratives about the process of formulation of the schizophrenia diagnosis, prognosis and treatment in the case of psychiatrists, were studied. This is a qualitative, multicenter study, informed by the theoretical approaches of Interpretative Phenomenological Analysis and Medical Anthropology held in Campinas, Rio de Janeiro and Salvador. The main methodological tool used for the production of narratives were focus groups. Procedures of the Explicitation Interview were incorporated. The categories identified in this study were Illness Experience, Diagnosis of Schizophrenia, Social Stigma, Recovery Experience, and Treatment and dynamic context of CAPS. The narratives that composed each category were presented and discussed in order to give visibility to the elements characterizing the narratives-experiences, indicating how it configures its complexity.

Key words: illness experience; narrative; schizophrenia. 